\title{
DESINFORMACIÓN Y CORONAVIRUS: EL ORIGEN DE LAS FAKE NEWS EN TIEMPOS DE PANDEMIA
}

\section{DISINFORMATION AND CORONAVIRUS: THE ORIGIN OF FAKE NEWS IN PANDEMIC TIMES}

(8) $\mathbb{R}^{\mathrm{C}}$ Marián Alonso-González . Universidad de Sevilla. España. malonsog@us.es

\section{Cómo citar el artículo:}

Alonso-González, M. (2021). Desinformación y coronavirus: el origen de las fake news en tiempos de pandemia. Revista de Ciencias de la Comunicación e Información, 26, 1-25.

http://doi.org/10.35742/rcci.2021.26.e139

\section{RESUMEN}

Un bulo es una noticia falsa propagada con algún fin. Diseñados para ser creídos, su origen es incierto, pero tras ellos suele esconderse "la compensación de un deseo frustrado de alguien o un grupo social, la necesidad de hacer pública la confidencialidad de intereses que trastornen el orden establecido, malentendidos o interpretaciones deformadas" (Kapferer, 1988, p.18). Las noticias falsas suelen basarse en el rumor, y el medio de éste es informal, creando nexos de complicidad, y es, precisamente, en esta confianza donde encuentra su máximo exponente, ya que no se suelen cuestionar los mensajes procedentes de nuestro círculo más íntimo. El objetivo fundamental de esta investigación estriba en identificar el origen de este tipo de informaciones, para ello optamos por una metodología de tipo cuantitativa que permita explorar los rasgos y aspectos formales de los bulos publicados en relación con la COVID-19, a fin de identificar diversos aspectos útiles para la detección de noticias falsas y aportando evidencias empíricas referidas a la desinformación. El resultado indica que tal y como anunció Tucídides en el siglo $\mathrm{V}$ a.C. en esta guerra contra la desinformación hay dos razones principales que motivan el origen de los bulos: el miedo y el interés, en sus diversas facetas, ideológico, económico y político, y para combatirlo resulta indispensable una adecuada alfabetización mediática de la sociedad, así como una comunicación oficial transparente y contrastada.

Palabras clave: Redes sociales, Fake News, Bulos, Comunicación, Desinformación, Posverdad, Verificación, Infodemia, COVID-19

\footnotetext{
1 Marián Alonso-González: Licenciada en Periodismo y Doctora en Comunicación Social por la Universidad de Sevilla, donde ejerce de profesora asociada, ha orientado su investigación a campos relacionados con la Comunicación 2.0, el Periodismo 3.0 y los lenguajes multimedia e interactivos.
} 


\section{ABSTRACT}

A hoax is a falsehood deliberately fabricated to masquerade as the truth. Their origin is uncertain and behind them often hides "the compensation of a frustrated desire of someone or a social group, the need to make public the confidentiality of interests that upset the established order, misunderstandings or distorted interpretations" (Kapferer, 1988, p.18). Fake news is false or misleading information presented as news and develop a shared complicity because people do not usually question messages that comes from their intimate circle. The main objective of this research is to identify the origin of fake news published in Spain related to COVID-19, for that, we opted by a quantitative methodology that allows us to explore features and useful aspects for their detection and providing empirical evidence regarding misinformation. The results show that as Tucídides announced in the 5th Century a. C. in this war against misinformation there are two main reasons that motivate the origin of the hoax: fear and interest, in several aspects, ideological, economic, and political, and to combat that is indispensable a development of media literacy in all sections of society, as well as a transparent, fluid, and official communication.

Keywords: Social networks; Fake News; Hoaxes; Communication; Misinformation; Post-Truth; Verification; Infodemic; COVID-19

\section{INTRODUCCIÓN}

El confinamiento y las restricciones de movimiento derivadas de la pandemia mundial del COVID-19 han provocado un aumento sin precedentes del tráfico de Internet y del uso de las nuevas tecnologías de la Comunicación. Este incremento, que el Instituto Nacional de Estadística (2020) estima en más de un millón de personas, hasta un total de 32,8 millones; se ha visto reflejado en todas las áreas, desde el uso de las redes sociales hasta el número de horas de televisión, pasando por el tiempo dedicado a los videojuegos o la cantidad de series y películas vistas en las plataformas online.

Aunque todavía es pronto para determinar si esta expansión tecnológica ha llegado para quedarse, sí es cierto que el entorno digital ha experimentado un gran avance en los últimos meses, sobre todo en ámbitos como las plataformas de trabajo en remoto y de videoconferencias, tecnologías que se han vuelto masivas y que se han adaptado a sectores como la educación o la medicina. Este boom tecnológico y digital ha probado su eficacia al acercar lo lejano, al tiempo que ha contribuido a multiplicar exponencialmente la cantidad de información que nos rodea. De hecho, según el informe Digital 2021, realizado por We Are Social (2021), el número de usuarios de internet en el mundo creció un 7,3\% durante el pasado año, llegando a los 4.660 millones.

La aparición del virus del COVID-19 y la incertidumbre generada por su origen, forma de transmisión y consecuencias ha provocado una gran dependencia informativa basada en la necesidad de dotar de significado a esta nueva situación de riesgo. Esto ha favorecido el "resurgimiento del protagonismo de los medios tradicionales, especialmente de la televisión, y la reconexión a las noticias de los ciudadanos más alejados de la información (Casero-Ripollés, 2020, p.1). 
Esta necesidad de información, unida al confinamiento, ha provocado que el nivel de piezas publicadas haya llegado a cotas inimaginables, hasta el punto de que la crisis sanitaria ha generado una infoxicación del ecosistema informativo lo que complica el acceso a "una información veraz y que ofrezca un análisis riguroso del contexto en el que vivimos" (López-Rico et al., 2020, p.78), generando lo que la Organización Mundial de la Salud ha denominado como 'Infodemia', un término que hace alusión a la sobreabundancia de información respecto a un tema, tanto rigurosa como falsa, lo que provoca incertidumbre y desconfianza entre los ciudadanos ante la imposibilidad de discernir la verdad de la mentira.

Según Lázaro-Rodríguez y Herrera-Viedma (2020, p.5), coincidiendo con el Decreto del Estado de Alarma en España se llegaron a publicar "45.294 noticias en medios digitales, lo que supone un incremento de casi el triple de noticias más que con respecto a las 15.434 de principios de marzo". Esta superabundancia informativa (Keane, 2013) ha generado un fenómeno sin precedentes y es que el nivel de asimilación de nuevas informaciones por parte de la audiencia se ha sobrepasado y esa saturación de contenidos ha provocado un fenómeno inverso, la desinformación. Afrontar una ingente cantidad de información modifica los hábitos de lectura por otros basados en la detección de palabras claves, una lectura no lineal y selectiva que implica un menor nivel de asimilación de los contenidos, hasta el punto de confundir leer con «hacer click», generando un gran cambio en la forma de pensar. Según un informe pionero sobre hábitos de lectura en Internet, dirigido por la University College de Londres y recogido por Grau (2008), los usuarios dedican alrededor de 8 minutos a leer un periódico electrónico y suelen saltar de un artículo a otro, sin volver atrás. De hecho, el 9,2\% de los lectores de prensa digital sólo lee el titular y el $63,7 \%$ el titular y alguna noticia de interés, unas cifras bastante similares a las de aquellos que consumen las noticias a través de las redes sociales, 15,1\% y 57,8\%, respectivamente.

Esta disminución cognitiva unida a una sobresaturación informativa, así como la inmediatez y la necesidad continuada de actualizar los contenidos, se convierte para Alonso-González (2019) en la piedra angular sobre la que se asienta el auge de las fake news que rápidamente se extienden y se dan por válidas. No existe una fórmula exacta para diferenciar la información cierta, y de ello se valen aquellos que, de forma intencionada, generan este tipo de noticias con voluntades tan diversas como diversión o generar alarma social.

En el contexto de la pandemia del COVID-19 el número de noticias falsas se ha disparado de forma proporcional al flujo informativo generado por la incertidumbre y la necesidad de conocimiento de la sociedad. Tan sólo durante el mes de abril de 2020 "el 44\% de los españoles encontró Fake News en las redes sociales y las aplicaciones de mensajería en los temas relacionados con el COVID-19" (Gallego, 2020), es por ello, que el presente estudio pretende determinar los distintos orígenes que tienen las noticias falsas relativas al coronavirus, así como la posible intencionalidad oculta tras su creación. Para ello se analizan hasta un total de 943 bulos publicados entre los meses de febrero y diciembre de 2020 en España y que han sido desmentidos por las plataformas de verificación de datos Maldita.es, Newtral y EFE Verifica, encargadas de combatir la infodemia. 


\subsection{Rumores y desinformación}

El medio del rumor es informal, tal como ocurría antes de la invención de la prensa. El rumor corre de boca en boca, confirmando lazos de confianza, lo cual provoca que creamos a ciegas en los mensajes que nos envían y que los distribuyamos masivamente sin llegar a ponerlos en duda. En la medida en que una información es admitida por un grupo, pasa a ser de conocimiento oficial: gana notoriedad, frecuenta las ruedas de conversación, se convierte en el asunto principal en torno al cual cada integrante del grupo se pronuncia y se posiciona. $\mathrm{Y}$ a cada repetición se afirma, ganando, así, su poder de convencimiento.

Con la aparición de las redes sociales y de las aplicaciones de mensajería instantánea el círculo de confianza se multiplica exponencialmente, y se dibujan círculos concéntricos que amplifican la difusión de ese mensaje a velocidades realmente vertiginosas. Junto al efecto cascada, que hace que la señal se refuerce cuanta más gente la recibe, entra en juego otro fenómeno, el de la "polarización de grupos" (Sunstain, 2009), y que genera una asimilación tendenciosa de las informaciones que proceden de la red de confianza del usuario, de manera, que las opiniones sobre un aspecto concreto se fortalecen cuando son compartidas con personas afines, pero también cuando se discuten con los contrarios, y de esa forma el individuo se afianza en sus aciertos y errores. Esto provoca que no se ponga en duda esa información y que, automáticamente, se acepte como válida, ya que a la hora de creer algo siempre entran en juego variables ideológicas como son los sentimientos, las opiniones y las motivaciones, lo cual explicaría por qué gracias a las redes sociales hechos incuestionables pierden la batalla frente a hechos alternativos y emociones.

De forma complementaria, las redes sociales suman a los mensajes otros parámetros igualmente difíciles de controlar como son el anonimato, la participación y la dificultad para borrar el rastro, asimismo, las aplicaciones digitales permiten que un contenido pueda ser manipulado para ensamblar, añadir o remover información, abriéndose paso con ello a procesos de re-encuadre, de reasignación de sentido o de recontextualización de la información que pueden alterar su significado. Cuando es la fuente quien busca al periodista, nos encontramos ante "un vertido de fuente" y esto suele darse con frecuencia en las redes sociales, las cuales favorecen que sus usuarios estén expuestos a las noticias eliminando la parte activa de búsqueda.

Pese a no ser un fenómeno nuevo, ya que durante el siglo XVIII fueron una herramienta de poder usada por los reyes y durante el siglo XX sirvieron a los totalitarismos de base propagandística, las Fake News han alcanzado cotas de inigualables proporciones durante este siglo 21, hasta el punto de que en 2017 fuera elegida 'Palabra del año' por el diccionario Collins. Hoy día, la búsqueda en Google del término Fake News arroja un resultado de 1.010.000.000 entradas, lo cual evidencia la magnitud de un fenómeno que no deja de crecer y que pone de relevancia la fragilidad del concepto de veracidad.

Para poder garantizar esta autenticidad informativa se hace imprescindible llegar a controlar los canales de producción y distribución de la información, y para ello es necesario averiguar qué se esconde detrás de la profusión de estas noticias falsas, 
por qué se ha magnificado este fenómeno, cuál es su origen y qué interés se oculta tras la creación deliberada de una información incierta, sobre todo, con temas tan sensibles y de gran calado social como es el coronavirus, la primera gran pandemia del siglo XXI.

En relación con los motivos existentes tras la creación y difusión de una desinformación, López-Borrull (2020b) establece una categorización que podría llegar a explicar quién es "el faker inicial". Por una parte, identifica a los bienintencionados, gente que no es entendida en el tema pero que no duda en dar consejos como si se tratase de un experto en la materia. En segundo lugar, los conspiranoicos, aquellos que dudan de cualquier información oficial y, sin embargo, dan credibilidad a los mensajes minoritarios que circulan en las redes sobre el origen de la enfermedad 0 sobre los efectos de las vacunas.

En tercer lugar, dice López-Borrull (2020b), se esconden los mensajes de odio al diferente, aquellos que aprovechan la crisis para estigmatizar a un colectivo determinado y los que usan la información con una evidente intencionalidad de hacer daño. Por último, estarían aquellos que buscan un rendimiento económico a través de la captación de tráfico hacia sus sitios web y los que responden a un reto viral. A estos últimos, la investigadora del Barcelona Centre for International Affairs, Carme Colomina, los denomina "gamberros 2.0", porque parte de estos bulos "responden a una broma 2.0" (Blanco, 2020).

\subsection{Fact-checking}

Para hacer frente a este contexto de inseguridad informativa y para dotar de transparencia al ecosistema digital online, el Consejo de la Unión Europea (2018) aprobó hace un par de años un Plan de Acción contra la Desinformación que recoge que los estados miembros apoyen la "creación de equipos de verificadores de datos e investigadores independientes multidisciplinares con un conocimiento específico de los entornos de información locales con objeto de detectar y exponer las campañas de desinformación entre las diferentes redes sociales y los medios digitales".

Conforme a esta directriz europea, España anunció en noviembre de 2020 la creación de un mecanismo contra la desinformación, dependiente del Consejo de Seguridad Nacional, y que pretende "prevenir, detectar, alertar, así como dar seguimiento y respuesta a este fenómeno" (Orden del Consejo de Ministros, 2020).

Medios de comunicación y profesionales del periodismo no han sido ajenos a esta problemática, y como respuesta a esta crisis de confianza se han sumado a iniciativas como The Trust Project, un proyecto internacional de verificación informativa, que "exige el cumplimiento de unos estándares básicos a fin de que las noticias cumplan unos criterios mínimos de credibilidad y fidelidad" (Alonso-González, 2019, p.36). De igual forma, ha emergido el fact-checking o chequeo de hechos después de que un planteamiento adquiera notoriedad pública, y que nada tiene que ver con la verificación previa a la publicación de una noticia. Este chequeo ex-post (Mantzarlis, 2018), busca fuentes primarias y de reputación sólida que puedan confirmar o refutar los contenidos publicados, así como la verificación de comentarios realizados por políticos y otros personajes relevantes. 
El censo de proyectos de verificación de la información elaborado por el Reporters' Lab de la Duke University (Stencel \& Luther, 2020) cuantifica en 304 las iniciativas de fact-checking en 84 países, un centenar más que el año anterior. De ellas, 5 se centran en exclusiva en la verificación de afirmaciones médicas y de salud pública, no obstante, la evolución de la pandemia ha incidido de forma significativa en el trabajo de estas entidades, por lo que la Red Internacional de Verificación de Datos ha creado un proyecto de colaboración contra la desinformación del COVID-19 que se ha denominado Alianza \#CoronavirusFacts.

En España existen una decena de verificadores entre los que destacan Maldita.es, EFE Verifica y Newtral, las tres están adheridas a la International Fact-checking Network, lo que implica un compromiso con la imparcialidad, la equidad, la transparencia de las fuentes, la financiación y la organización, así como un compromiso con la transparencia de la metodología y con correcciones abiertas y honestas (Pozo-Montes y León-Manovel, 2020).

Puesto que las fake news no se combaten con censura, sino con más noticias y más formación (López-Borrull et al., 2018), profesionales de la información y redes sociales se han aliado para encontrar nuevas formas que permitan luchar contra esta problemática. Así, la plataforma de mensajería WhatsApp ha limitado el reenvío de mensajes para frenar el avance de los bulos, mientras que las principales redes sociales han desarrollado programas para la detección de informaciones falsas. El objetivo principal es poner la tecnología al servicio de la información veraz y lograr aminorar el flujo de noticias falsas que circulan por la red.

En este sentido, Facebook, según su directora de comunicación Lola Baños (comunicación personal, 10 de febrero de 2020), elimina hasta un millón de cuentas falsas al día y ha puesto en marcha un sistema de avisos, similar al Fast Check de Google, para indicar a los usuarios si una noticia es falsa o no. Para ello, ha creado un equipo exclusivo, que opera en 80 países del mundo y hasta en 60 idiomas, encargado de verificar informaciones y dotar a las noticias del timeline de un velo que indica la palabra "falsa" si no puede ser probada como cierta.

En colaboración con portales como Snopes y Politifact, Facebook (2020) rastrea todo lo que sucede en la red social para reducir la difusión de las Fake News, al tiempo que apuesta por programas de alfabetización mediática que permitan fomentar el espíritu crítico entre sus usuarios. En su lucha contra las noticias falsas, Facebook ha retirado más de 12 millones de piezas en el último año y ha marcado como "falsa" 167 millones de informaciones relativas al COVID-19, según Lola Baños (comunicación personal, 10 de febrero de 2020).

Twitter también ha implementado un sistema que permite señalar las noticias falsas. La plataforma ha ideado un sistema de etiquetas que alerta sobre el contenido no probado y que introduce una marca de agua sobre aquel tuit cuya información no ha sido verificada. Desde enero de 2021, la red social está probando una sección independiente, denominada Birdwatch-de momento sólo disponible para un pequeño grupo de usuarios de Estados Unidos- que permite identificar información engañosa y escribir notas que brinden un contexto informativo. 


\section{OBJETIVOS}

El objetivo fundamental de esta investigación estriba en identificar el origen de las informaciones falsas que en relación con el coronavirus han circulado en España entre los meses de febrero y diciembre de 2020 y que fueron desmentidas por las principales plataformas de fact-checking de nuestro país.

En este abordaje hemos seguido la clasificación propuesta por López-Borrull (2020a), la cual ha sido completada con tres nuevas categorías derivadas de nuestro estudio, de forma que enriquece investigaciones precedentes aportando nuevas evidencias sobre los rasgos y aspectos formales de los bulos publicados sobre la COVID-19, al tiempo que permite identificar el interés oculto tras la creación de los mismos, a fin de perfilar algunas certidumbres empíricas referidas a la desinformación y a las consecuencias que generan.

\section{METODOLOGÍA}

La metodología aplicada en esta investigación es de tipo cuantitativa y atiende, en primera instancia, a la exploración de noticias falsas sobre la COVID-19 para poder establecer en número y porcentaje los distintos orígenes de los bulos.

El desarrollo de esta investigación se ha realizado en tres etapas que podemos identificar como recolección de noticias, análisis del discurso para poder reconocer la estructura y estrategias de los argumentos presentados, y clasificación de las piezas en base a la categorización establecida por López-Borrull (2020a) para identificar su origen.

Para la búsqueda de informaciones falsas se ha recurrido al repositorio de piezas desmentidas por la alianza de fact-checkers que, coordinados por la Red Internacional de Verificación de Datos (IFCN), se dedica a combatir la infodemia. En concreto, el estudio se ha centrado en el conjunto de noticias detectadas y desmentidas por las plataformas Newtral, Maldita.es y EFE Verifica en España, para su selección se ha tenido en cuenta sus índices de audiencia, un acceso fiable de sus archivos a lo largo del tiempo y que fuera signataria del sello IFCN.

Para la localización de las noticias se ha efectuado un seguimiento de las tres plataformas entre los meses de febrero y diciembre de 2020, localizando los términos "bulo", "fake news", "COVID-19" y "coronavirus". Una vez revisadas todas las piezas, y tras un proceso de cribado que permitió eliminar aquellas unidades que se repetían, se obtuvo una muestra total de 943 piezas (Maldita.es, 602; Newtral, 225 y EFE Verifica, 116) cuyas observaciones se registraron en una plantilla creada con una hoja de cálculo Excel y cuyos datos fueron procesados con SPSS, un programa estadístico informático muy usado en las Ciencias Sociales.

Para el estudio cuantitativo se ha atendido a variables como número de unidades, mes, formato que presentaban (texto, audio y vídeo) y plataforma de difusión utilizada (Internet, redes sociales y las aplicaciones de mensajería instantánea WhatsApp y Telegram). Para mostrar los encuadres que estas noticias falsas pretenden transmitir 
respecto al COVID-19 se ha optado por el análisis de contenido, para ello, se ha procedido a la identificación de patrones comunes que permitan determinar su origen. Para el análisis crítico del discurso, se ha tabulado la información en base a la temática de sus titulares, el análisis del texto de la noticia y los elementos adicionales que presentaban (imágenes y vídeos) para, de esta manera, comprender el significado global del texto, delimitar el tema principal del discurso periodístico y establecer la intencionalidad y motivaciones de sus creadores.

Las unidades de estudio se fijaron en base a la propuesta que, sobre el origen de los bulos, hace López-Borrull (2020a):

- Rendimiento económico: buscan atraer visitas a un sitio web.

- Provecho ideológico: tienen por objeto estigmatizar a un grupo social y alimentar discursos xenófobos.

- Conspiranoicos: bulos científicos globales que pretenden imponer otra forma de ver el mundo a la par de expandir sus ideas.

- Gamberros 2.0: aspiran a lograr un impacto viral y se toman la difusión o creación del bulo como un reto.

Completada la codificación se procede a realizar una segunda revisión de los ítems analizados, pues durante el estudio se comprueba que un $28 \%$ de los bulos no se ajusta a las categorías anteriormente descritas, es por ello, que se procede a la codificación de estas 264 piezas en torno a tres nuevas categorías surgidas del análisis de contenido. En base a sus fines retóricos y para delimitar la intención presente en el diseño y puesta en circulación de estas noticias las nuevas categorías fueron:

- Objetivos políticos: Noticias en las que la desinformación en relación con el COVID-19 procede "de agentes políticos" (EFE, 2020).

- Carácter Geoestratégico: Informaciones que desencadenan tensiones sistémicas de la gobernanza mundial con consecuencias de largo alcance en las relaciones internacionales.

- Fraude: Bulos que tienen por objeto cometer delitos telemáticos como pueden ser el pishing o el secuestro de información de los dispositivos electrónicos.

Sobre la base final de este manual de codificación se procede, nuevamente, al análisis de los 943 bulos, los cuales se clasifican en base a las siguientes variables principales.

1. Formato: texto, audio, vídeo

2. Plataforma de publicación: internet, redes sociales, WhatsApp y Telegram.

3. Origen de los bulos: económico o click-bait, ideológicos, conspiranoicos, Gamberros 2.0, políticos, geoestratégicos y fraude.

Para alcanzar la deseable consistencia del estudio y pese a la limitación de contar con un único codificador, la doble revisión permitió aclarar los puntos de discrepancia y contabilizar que el margen de error no llega al 1\%. Con posterioridad, se procedió a una cuarta y última codificación de la muestra cuyos resultados se muestran a continuación. 


\section{DISCUSIÓN}

La COVID-19 ha provocado un aumento exponencial de la desinformación en todo el mundo por el proclive caldo de cultivo del miedo que provoca esta enfermedad, de la que aún se desconoce su origen y que rápidamente ha alcanzado el nivel de pandemia, pero también por el papel catalizador generado por las redes sociales y las plataformas de mensajería instantánea.

El coronavirus en la era de las Fake News y la posverdad ha propiciado un aluvión de bulos, relatos y discursos de todo tipo que obligan a hacer un esfuerzo para distinguir la verdad de la mentira y la responsabilidad de la negligencia. A lo largo del presente estudio se han analizado un total de 943 bulos relacionados con la COVID-19 en España y que han sido desmentidos por las principales plataformas de fact-checking de nuestro país (Maldita.es, Newtral y EFE Verifica) entre el 1 de febrero y el 31 de diciembre de 2020.

De ellos, 516 bulos han sido difundidos a través de WhatsApp y Telegram, 369 mediante las redes sociales (Facebook y Twitter, principalmente) y 58 a través de Internet. Esto supone que las aplicaciones de mensajería instantánea han sido las responsables de la difusión del $55 \%$ de las noticias falsas (Ver Gráfico 1).

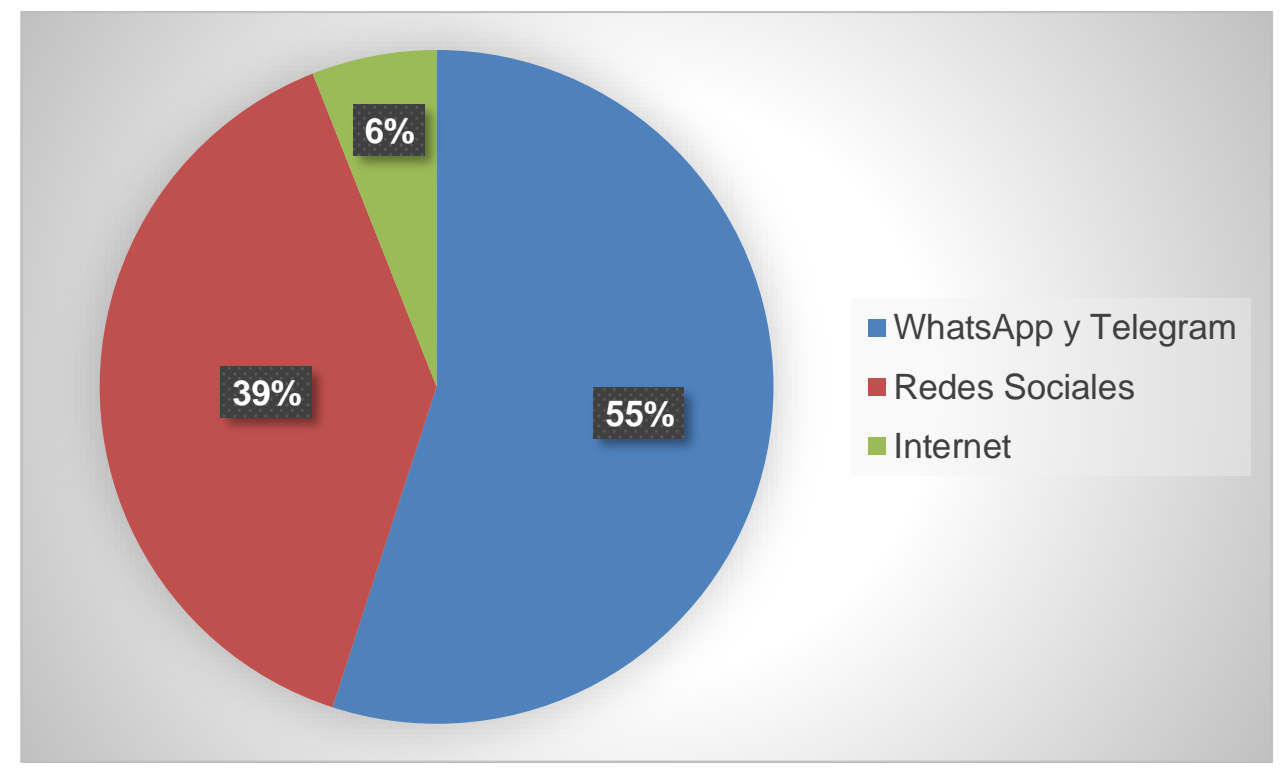

Gráfico 1: Modo de difusión de las Fake News sobre la COVID-19 Fuente: Elaboración propia

En cuanto al formato elegido para la transmisión de estas noticias falsas, el $85 \%$ fue de tipo texto, el $11 \%$ se distribuyó en formato vídeo y un $4 \%$ fueron audios.

Atendiendo a su origen, y tal y como puede apreciarse en el siguiente gráfico (Ver Gráfico 2), los más abundantes son aquellos que tienen un origen conspiranoico (36\%) y que, bien, niegan la existencia de la COVID-19 o apuntan a los efectos perjudiciales de las vacunas. 
El segundo grupo más numeroso, presente en el $25 \%$ de los bulos, son aquellos que tienen por objeto la viralidad para obtener un rédito económico derivado del fenómeno click-bait. Le siguen (19\% del total) los que tienen un origen político y que buscan generar desafección a las instituciones del gobierno o perjudicar a la imagen de los principales políticos, generalmente, desacreditándolos ante la opinión pública.

El 20\% restante se reparte de la siguiente manera: un $7 \%$ es de tipo gamberradas 2.0; otro $7 \%$ persigue intereses geoestratégicos, un $7 \%$ es de origen ideológico (con especial incidencia en la xenofobia y la aporofobia); y un $2 \%$ busca perpetrar un fraude o expandir un virus $(2 \%)$.

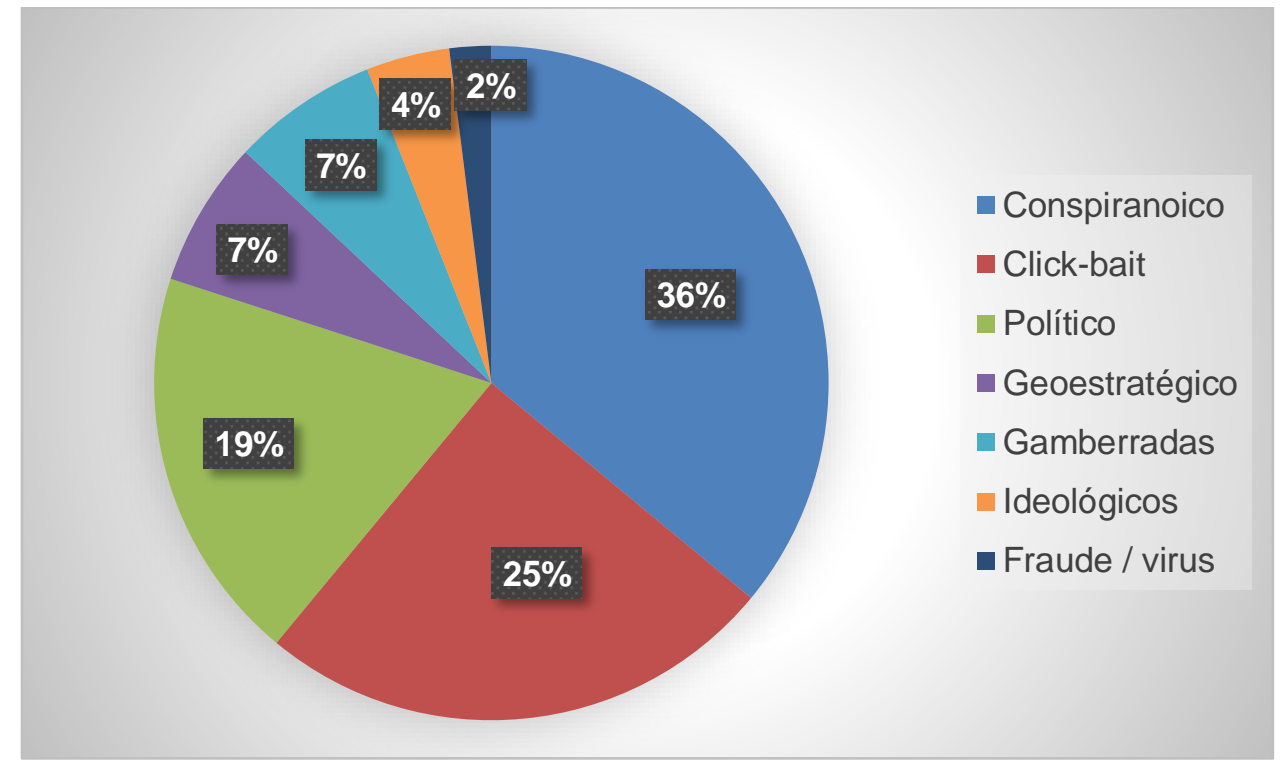

Gráfico 2: Origen de las Fake News publicadas en torno a la COVID-19

Fuente: Elaboración propia

Entre los mensajes de audio difundidos por WhatsApp, los más abundantes son los de origen conspiranoico (46\%), seguidos de los virales que persiguen el click-bait $(23 \%)$ y los políticos (14\%). El resto se reparten de la siguiente manera: ideológicos (6\%), gamberros $2.0(8 \%)$ y fraude $(3 \%)$.

De igual forma, los bulos de tipo conspiranoicos son los más abundantes en formato vídeo (49\%), seguidos del tipo click-bait (26\%) y los de origen ideológico (11\%). En menor medida, $7 \%$, encontramos los de origen político, gamberros $2.0(6 \%)$ y los de origen geoestratégico (1\%).

\subsection{Conspiranoicos}

Los bulos más comunes distribuidos por los conspiranoicos tienen por objeto la negación de la pandemia (40\%). A ello ha contribuido, fundamentalmente, una plataforma llamada 'Médicos por la verdad', creada a finales de julio de 2020, y que lleva desde que comenzó la enfermedad difundiendo bulos sobre el coronavirus, hasta el punto de que el Consejo General de Colegios Oficiales de Médicos de España ha 
iniciado los trámites de apertura de un expediente informativo contra este grupo de negacionistas para valorar si vulneran el Código Deontológico.

Un segundo grupo de bulos de importante consideración, también con origen conspiranoico, es aquel que asegura que tras la pandemia se esconden los intereses ocultos del "nuevo orden mundial" (36\%). A este grupo pertenecen los mensajes que mantienen que el $5 \mathrm{G}$ es la causa de la propagación del virus o que el uso de mascarillas provoca hipoxia, una teoría que sirve de base a los movimientos "antimascarillas" que han ido surgiendo por todas partes del planeta y que no dudan en enfrentarse a las autoridades y saltarse las recomendaciones médicas porque creen que todo es fruto de una conspiración orientada a restringir los derechos ciudadanos.

La influencia de este tipo de informaciones falsas en la sociedad es tal que en Estados Unidos hay encuestas que señalan que "alrededor de un $25 \%$ de sus ciudadanos cree que, 'definitivamente' o 'probablemente', el brote de coronavirus fue planeado intencionalmente por personas poderosas" (Ocaña, 2020).

Por último, se encuentran aquellas noticias que tienen por objeto desacreditar el funcionamiento de las vacunas (24\%), atribuyéndole efectos adversos que nada tienen que ver con la realidad. Entre estos, destacan, sobre todos los vídeos en los que algunos doctores aseguran que los vacunados contra el coronavirus podrán contagiar a personas sanas y que las futuras vacunas causarán la esterilidad de aquellos que se la inoculen. También con ánimo de alimentar la controversia y la alarma social en torno a las vacunas han circulado audios en los que se asegura que en los colegios están vacunando a los niños sin el permiso de sus padres.

\subsection{Click-bait}

Uno de cada cuatro bulos difundidos tiene intención de beneficiarse del fenómeno click-bait, que busca llamar la atención con títulos que invitan al click a fin de conseguir visitas mediante el uso de valores extra periodísticos y que provocan que cada vez sea más difícil discernir su verisimilitud.

Por lo general, este tipo de noticias suele caracterizarse por la inserción de titulares llamativos y poco rigurosos que pretenden funcionar como "anzuelos", pudiendo distorsionar la realidad e incrementar la desinformación, una práctica que queda muy cerca de la manipulación y puede ser considerada un daño colateral en la guerra por conseguir una mayor audiencia.

Dentro de este grupo, se observa que la inmensa mayoría (58\%) está conformada por noticias que, sin contar con base científica, afirman haber dado con la clave para no contagiarse y que apuestan por prácticas tan peligrosas como beberse la orina 0 consumir cocaína o ketamina. La falta de tratamiento para la COVID-19 ha multiplicado el negocio de pseudoterapeutas y pseudocientíficos que manifiestan que la lejía, la pasta de dientes, el metanol o la plata son el remedio para acabar con el virus. Este tipo de informaciones falsas resultan extremadamente peligrosas y su rápida extensión entre la población ha llevado a la Organización Mundial de la Salud 
a abrirse una cuenta en TikTok para proporcionar consejos de salud pública fiables y adecuados.

Por otra parte, un $33 \%$ de estas informaciones virales busca generar miedo entre la población, ya que éste es uno de los elementos más poderosos dentro de los procesos de producción de subjetividades que buscan la homogenización y la desaparición de las diferencias, así sea a costa de la liquidación de los diferentes (Useche, 2008). La emoción siempre gana a la razón y esta es la base sobre la cual se asienta la viralidad de este tipo de mensajes, de hecho, según Ricou (2020), una información que genera miedo tiene más posibilidades de ser compartida, aunque sea mentira, que una noticia veraz. Este es el caso de cabeceras de medios que son manipuladas para lanzar noticias engañosas sobre olas de coronavirus sin precedentes, los falsos confirmados en diversas localidades de España, o los ficticios brotes que han obligado a cerrar colegios e institutos.

Por último, el 9\% difunde inexactitudes o falsedades en la línea de vídeos de TikTok, o curiosos de animales que aprovechando el confinamiento bajan a las ciudades. Es el caso de los cisnes que nadan en los canales de Venecia, o los ciervos en la playa de Matalascañas, en Huelva, que, incluso, fue dada como una noticia válida en la sección "El Tiempo" del informativo de Telemadrid (Alcalde, 2020). Otras, incluso, apuntan a que el presidente de Rusia habría dado la orden de soltar 500 leones para obligar a la población a respetar el confinamiento (Ver Figura 1).

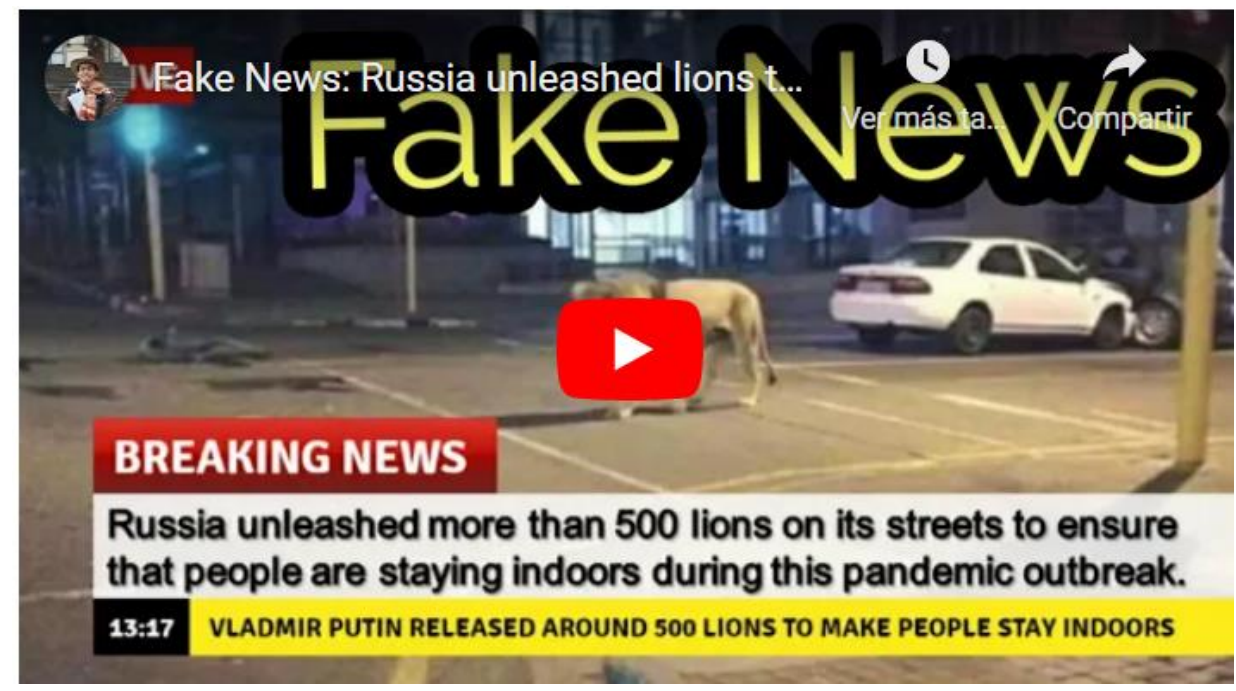

Figura 1: Fake News sobre la suelta de leones en Rusia Fuente: Reuters

\subsection{Políticos}

Un importante punto de origen de los bulos (19\%) son los líderes de opinión que pueden representar, o no, a intereses de partidos políticos o empresas. De hecho, según López-Borrull (2020b), los partidos, más que lanzar directamente un bulo, lo que hacen es sembrar la duda sobre algún asunto con el objetivo de que sus seguidores lo den por cierto en las redes sociales. 
A lo largo de esta investigación han sido detectadas y analizadas 162 noticias falsas cuyo origen está relacionado con los diversos partidos políticos que copan el espectro nacional, autonómico y local. En ocasiones, estos bulos han sido puesto en conocimiento de la Fiscalía, tal es el caso del Cabildo de Fuerteventura que ha denunciado los bulos de una web vinculada al consejero Domingo Pérez (PP) por publicar información falsa en la que sostiene que "el Gobierno estudia volver a decretar el estado de alarma en Fuerteventura si continúan llegando pateras con inmigrantes con Covid-19" (Diario de Fuerteventura, 2020).

Un reciente estudio sobre la infodemia en 6 países de Europa (Nielsen et al., 2020) revela que los políticos, en un 43\%, y el Gobierno, en un 34\%, son, a juicio de los españoles, las principales fuentes de información falsa. Estas percepciones sociales provienen de la manera en la que las distintas formaciones políticas han utilizado el COVID-19 para obtener un rédito electoral, intentado polarizar a las audiencias a través de lo que puede denominarse un sesgo partidista.

Así, el Partido Popular acusaba al Gobierno de no contactar con empresas españolas encargadas de la distribución y fabricación de los tests rápidos de detección de antígenos del virus. El propio secretario general del partido, Teodoro García Egea, insistía en la cuestión con varios tuits en este sentido y Ana Rosa Quintana se hacía eco de la noticia en su programa, viéndose obligada a desmentir la información 24 horas después (Ver Figura 2).

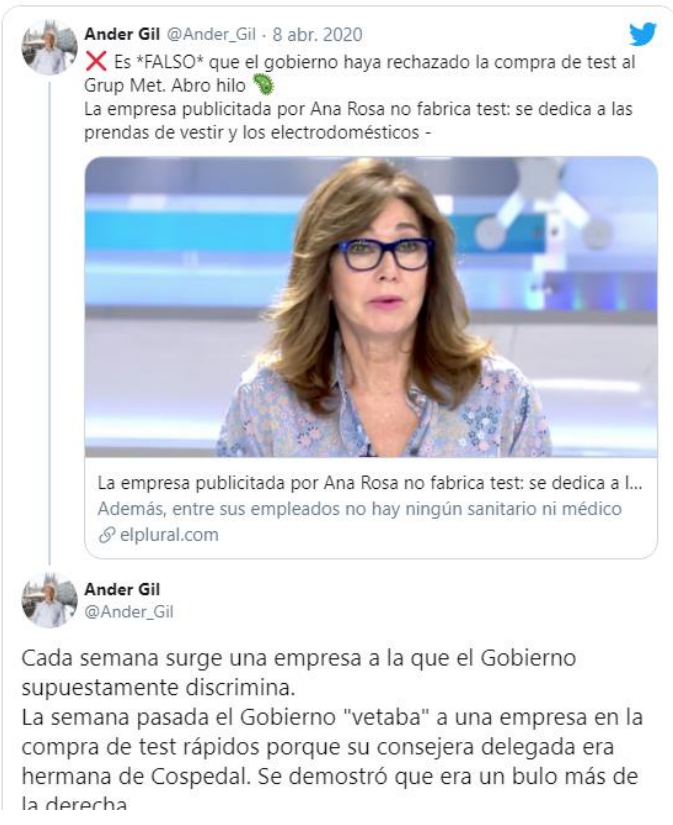

Figura 2: Fake News sobre el rechazo de la compra de test Fuente: @Ander_Gil, portavoz socialista en el Senado

Es

También el Partido Socialista denunciaba en el Parlamento de Andalucía (Ver Figura 3) la supuesta escasez de equipos de protección individual (EPIs) en el hospital Puerta del Mar de Cádiz, una información que se había viralizado a través de WhatsApp con datos inventados y que la propia Policía Nacional, en un comunicado remitido a los 
medios, tuvo que desmentir y recordar a los ciudadanos "que no contribuyan a viralizar bulos alarmistas».

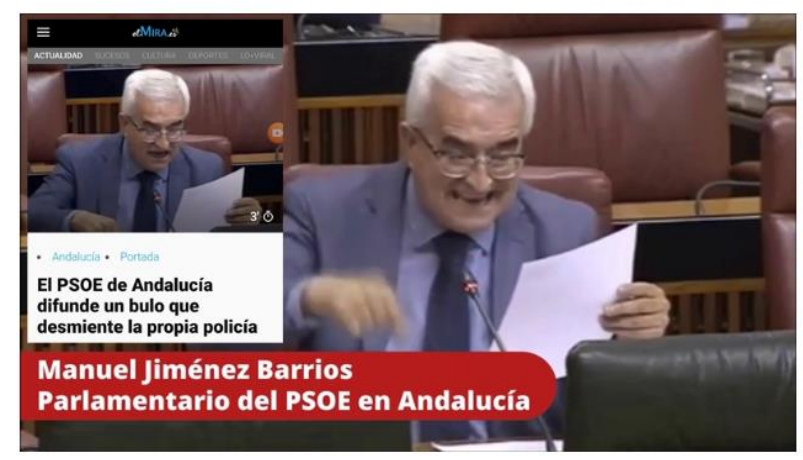

Figura 3: Jiménez Barrios (PSOE) difundiendo un bulo en el Parlamento Fuente: Horasur.com

Por su parte, Vox se ha convertido en altavoz de noticias inciertas, como la que anunciaba que el Centro Superior de Investigaciones Científicas advirtió al Gobierno desde un primer momento de la gravedad del coronavirus, o aquellas que aseguraban que los okupas podían darse de alta en el padrón municipal para poder acceder a las ayudas del COVID-19, incluida la renta mínima. La información también fue inicialmente compartida por dirigentes de Ciudadanos como Toni Cantó que, tras cerciorarse de su falsedad, decidió borrar todo rastro.

Asociaciones y movimientos organizados al calor de las ideologías políticas se encuentran en el origen de muchas de las informaciones falsas. Dos grupos especialmente prolíficos en estos menesteres son "España viva" y "Resistencia Democrática". El primero se define como un grupo de apoyo a Vox y, el segundo, como un "movimiento transversal" que no está "vinculado a ningún partido político, y en el que caben "todas las ideologías", a excepción del "comunismo", que a su juicio representa el Ejecutivo de coalición, quienes tratan de llevar a España hacia "una dictadura de corte chavista" (Sánchez Castrillo, 2020).

Los bulos creados por este tipo de plataformas sobre el COVID-19 han puesto en jaque la ciberseguridad a base de campañas de desinformación o bulos susceptibles de generar "desafección a instituciones del Gobierno". El caso más sonado es el de una cadena de mensajes que acusa al Gobierno de genocidio de ancianos, al afirmar que se obliga a las residencias a encerrar en sus habitaciones a los mayores contagiados de coronavirus e impedirles ir al hospital para ser tratados (Ver Figura 4). 


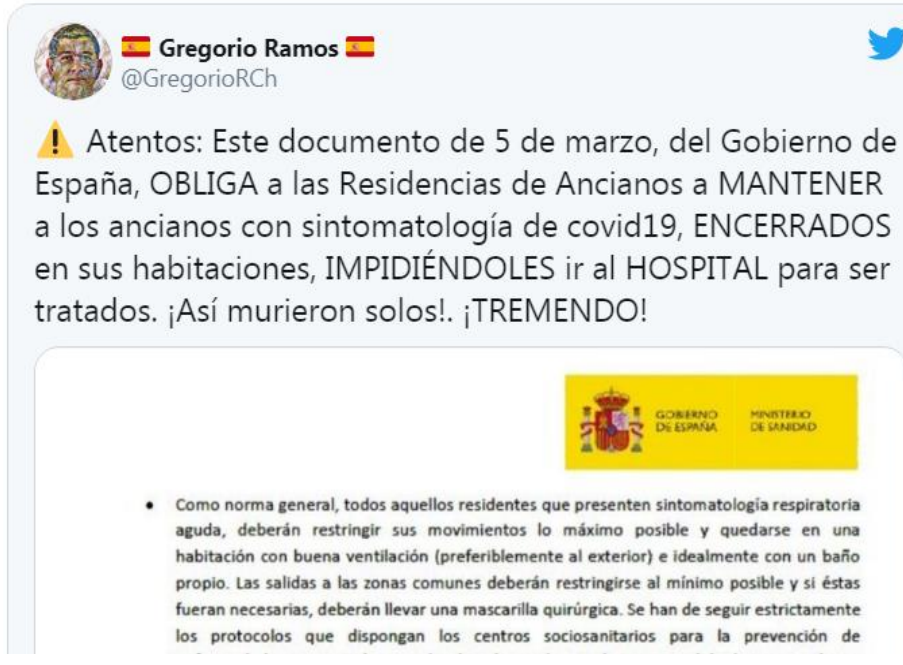

Figura 4: Bulo sobre el genocidio de ancianos decretado por el Gobierno Fuente: Twitter

Este tipo de noticias falsas también están orientadas a menoscabar la imagen pública de determinados políticos entre los que destacan el presidente del Gobierno, Pedro Sánchez, y el director del Centro de Coordinación de Alertas y Emergencias Sanitarias, Fernando Simón.

Pedro Sánchez se ha convertido en el protagonista de 14 bulos que le acusan, entre otras cuestiones, de haber viajado a Doñana con su familia durante el confinamiento, disponer de una planta exclusiva en el hospital Puerta del Hierro para su familia o de haber sido imputado por el Tribunal de la Haya por genocidio en relación con la COVID-19. Por su parte, Fernando Simón ha sido objeto de montajes y de noticias falsas hasta en 7 ocasiones, con intención de desprestigiar su labor al frente de la pandemia. Entre otras, se le atribuye haber "reconocido que se incluyen fallecidos por otras causas como si fueran por COVID-19" o de haber mantenido una reunión con el hijo de George Soros, cuando en realidad, se trata de Sergio Farjado, alcalde de Medellín.

\subsection{Ideológicos}

La motivación ideológica se convierte en el punto de origen de numerosos bulos que buscan, fundamentalmente, estigmatizar a sectores de la sociedad como, por ejemplo, los inmigrantes y relacionarlos con el terrorismo 0 , más recientemente, con el coronavirus. El miedo al contagio, la falta de recursos sanitarios y la crisis económica derivada de las restricciones impuestas por el COVID-19 han generado un ambiente propicio para el incremento de la xenofobia y la aporofobia, un fenómeno que no es nuevo, pues según publica Alexandre White (2020) en The Lancet, ya estuvo presente en las epidemias del siglo XIX, cuando a los no europeos se les culpaba de diseminar la enfermedad.

En este sentido, White recuerda las cuarentenas a las que eran sometidos indios y asiáticos antes de entrar en Ceilán ante el peligro de que el cólera o la peste supusiera un revés económico para el floreciente mercado del té, o cómo las Convenciones 
Sanitarias Internacionales de 1892 a 1938 percibían a los musulmanes que viajaban a Europa tras haber realizado la peregrinación a La Meca como una amenaza potencial a la hora de propagar enfermedades y que, por ello, se les imponían duras cuarentenas.

El miedo al extranjero y a los pobres está presente en el 7\% de las desinformaciones que circulan en torno al coronavirus. La mayoría de estas piezas giran en torno al inmigrante como causa de la expansión de la pandemia, siendo habituales audios de WhatsApp en los que se manifiesta la llegada a España de extranjeros contagiados sin que las autoridades hagan nada al respecto. Este es el caso de los audios que relatan cómo 33 inmigrantes positivos de COVID-19 habrían llegado a Fuerteventura y que nueve de ellos habrían escapado del confinamiento, lo que habría motivado al Cabildo a debatir si confinaba o no la isla. Ante la rápida viralización del mensaje, narrado en primera persona, la institución oficial tuvo que salir al paso y desmentir la información.

La lista de bulos que culpan a los inmigrantes de los problemas y que expanden la xenofobia, el racismo y la aporofobia es larga y variada, desde supuestos procedimientos de regulación anunciados por el Gobierno, la percepción del ingreso Mínimo Vital para los llegados en pateras y su denegación a los parados españoles, hasta las 500 pateras en Argelia a punto de zarpar a España con personas infectadas y que, en realidad, eran barcos de pesca (Ver Figura 5).

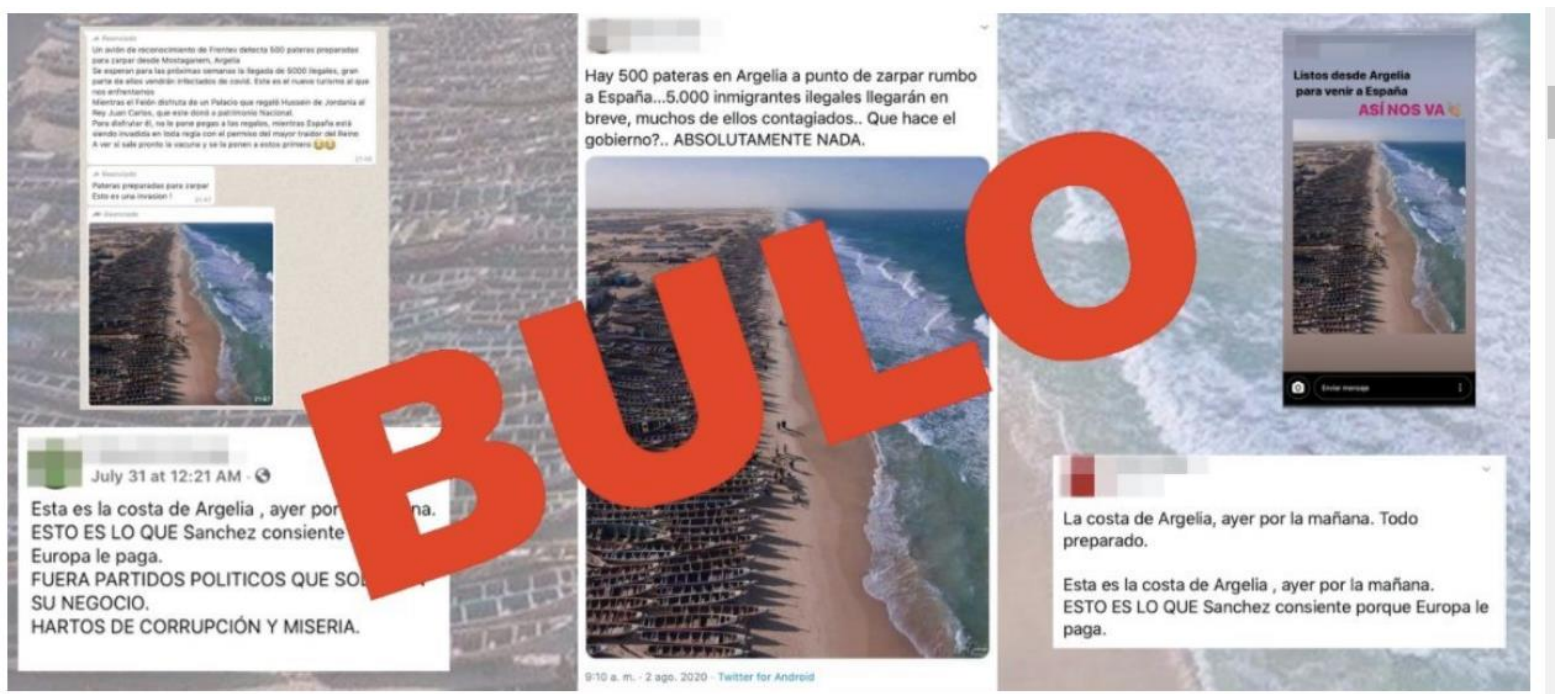

Figura 5: Bulo sobre pateras a punto de partir para España

Fuente: Maldita.es

\subsection{Gamberros 2.0}

Si en la década de los 90 los denominados "gamberros" aprovechaban el terrorismo de ETA para llamar a instituciones oficiales y de enseñanza para dar avisos de bombas y desestabilizar el sistema, en la era digital las nuevas herramientas de comunicación social han puesto al alcance de su mano una nueva forma de cometer actos de incivilidad. Por lo general, se trata de bromas que tienen por objeto crear confusión y, para ello, no dudan en hacer referencia a medios de comunicación o 
mostrar el logotipo de instituciones que gozan de credibilidad para favorecer la viralización de sus mensajes.

Pese a que este tipo de noticias ofrece muchas veces datos contradictorios e ilógicos, en una época en la que la incertidumbre marca el día a día, la necesidad de información actualizada lleva a la ciudadanía a dar pábulo a noticias que generan confusión. Así, por ejemplo, encontramos las falsas cartas que anunciaban la suspensión de clases en Castilla y León (Ver Figura 6) y en Andalucía, el retraso de las pruebas de Selectividad en agosto o el uso de las conexiones de Zoom para distribuir malware y capturas de datos personales.

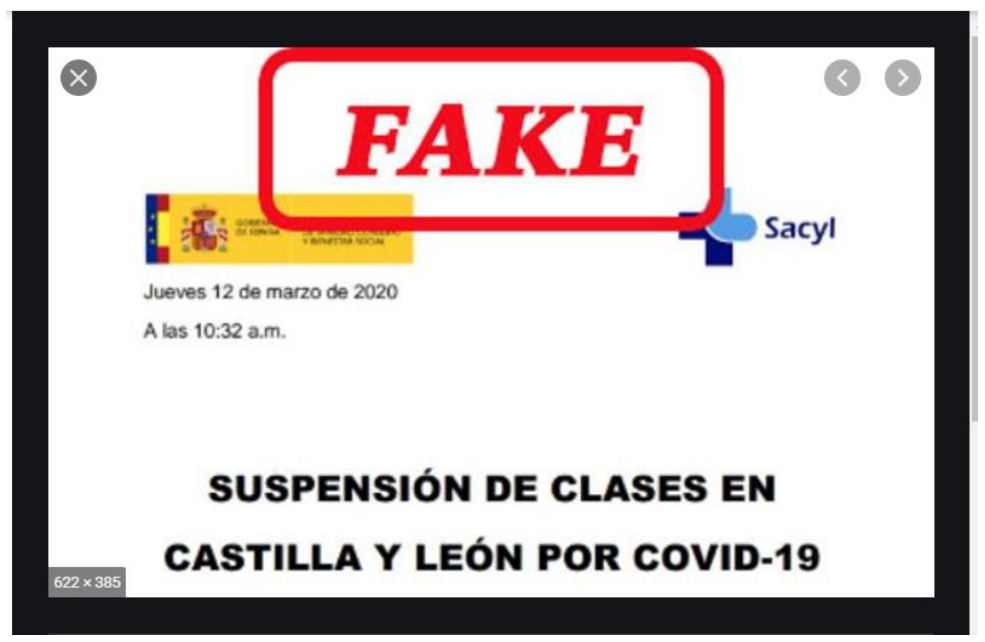

Figura 6: Falso comunicado de suspensión de clases en Castilla y León Fuente: EFE Verifica

Este tipo de gamberradas supone el $7 \%$ de las noticias falsas detectadas en torno a la COVID-19 y, frente a su supuesta inocuidad, un $2 \%$ está orientada a generar un evidente daño económico a empresas y comercios. Así, encontramos desde el supuesto cierre de locales y bares en Badajoz debido a un repunte de casos de coronavirus, a otros en los que se apunta directamente a un establecimiento, como en caso del WhatsApp que difundía que una de las cocineras del Bunker Beach Club de Sotogrande, en Cádiz, había dado positivo. Otros negocios perjudicados han sido la peluquería Viveros en Galicia, el Lidl del barrio de Los Llanos, en Gijón, e, incluso, el servicio de Cardiología del Hospital Virgen Macarena de Sevilla.

\subsection{Geoestratégicos}

Las campañas de desinformación con un claro fin geoestratégico representan el 7\% del total de las noticias falsas que circulan en torno a la COVID-19. Su origen se puede encontrar servicios de inteligencia y los ejércitos del ciberespacio, según Yolanda Quintana, experta en seguridad (Gonzalo, 2020), y tienen el claro objetivo de crear acciones de intoxicación informativa para desacreditar a otros países.

La pandemia ha entrado de lleno en "las estrategias de propaganda y desinformación de China, Rusia, Estados Unidos y la Unión Europea” (Rouco, 2020, p.19). El gran 
perjudicado ha sido China, objeto de estigmatizaciones, hasta el punto de que el propio presidente Trump no ha dudado en hablar del "virus chino".

Entre los múltiples bulos que circulan sobre el origen de la pandemia encontramos los que afirman que el coronavirus se produjo por tomar sopa de murciélago (Ver Figura 7) o que las serpientes que se comen a esos murciélagos se convierten en portadoras del virus. Otros, directamente, apuntan a que la compra de productos de países afectados puede contagiar, bulos que provocan la desestabilización de la economía y perjudican a determinados países.

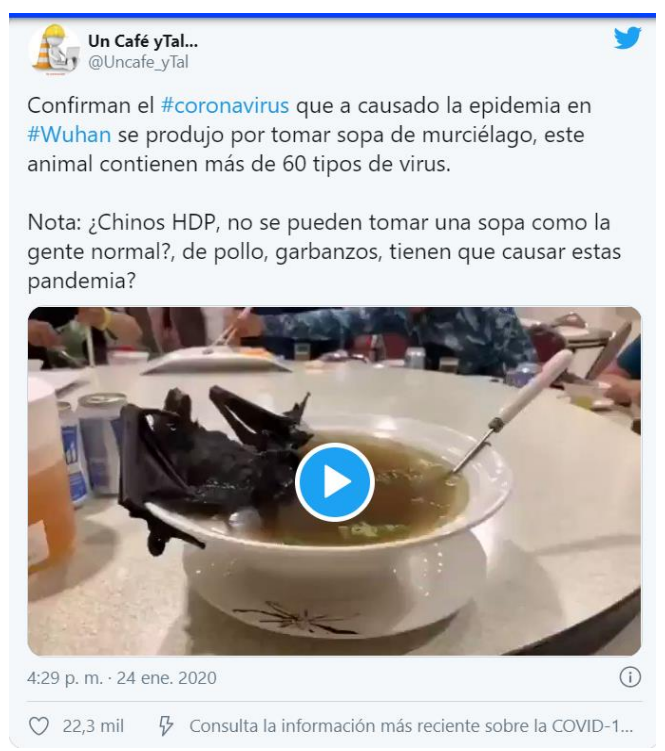

Figura 7: Falso vídeo en Twitter sobre la sopa de murciélago en Wuhan Fuente: EFE Verifica

Sin embargo, las desinformaciones sobre el COVID-19 también se han convertido en un arma arrojadiza entre el bloque sino-ruso y Estados Unidos. De hecho, Rusia ha creado numerosos bulos y teorías conspiratorias, entre las que podemos destacar los que apuntan a Bill Gates y George Soros como creadores del COVID-19 (Ver Figura 8), que la principal fuente de expansión del coronavirus fue un laboratorio estadounidense en Armenia, que la Unión Europea abandonó a Italia a su suerte y que solo Rusia y China la ayudaron en plena primera ola de la pandemia; o que la causa única del virus es el matrimonio gay. 


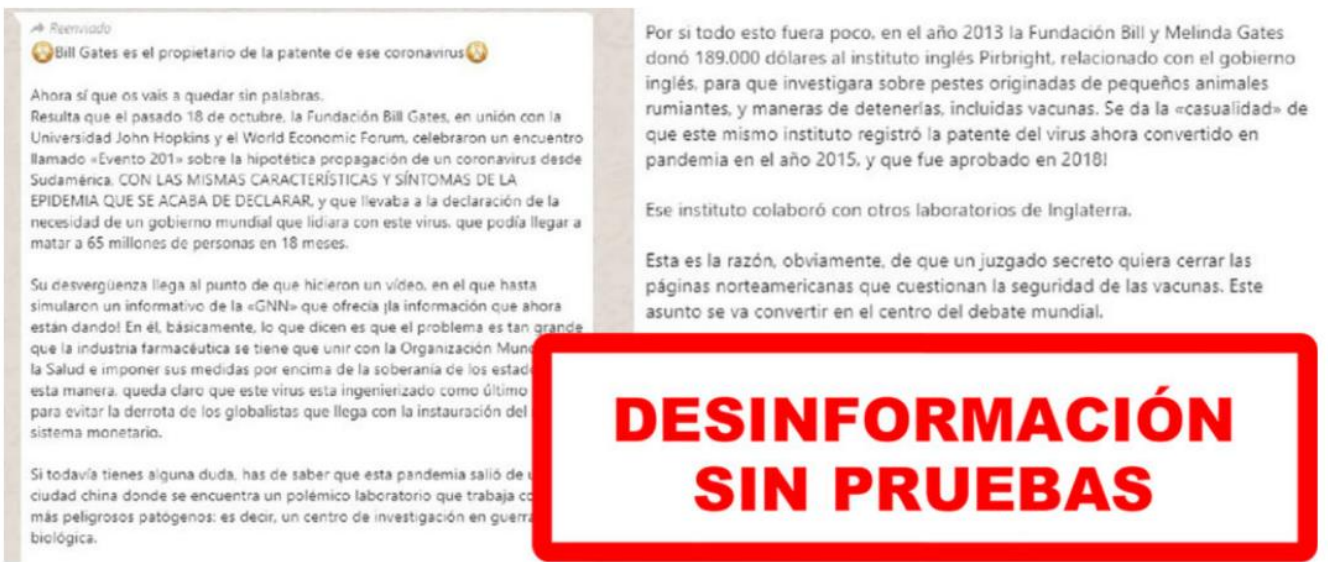

Figura 8: Whatssap que afirma que Bill Gates es el propietario de la patente del COVID-19

Fuente: Maldita.es

\subsection{Fraude o virus}

Los bulos que persiguen un fraude o la transmisión de un virus informático constituyen el $2 \%$ del total. A lo largo de esta investigación se han detectado 2 noticias falsas difundidas por correo electrónico y cuyo objetivo era infectar los dispositivos electrónicos. Estos ataques de malware procedían, supuestamente, del Ministerio de Sanidad y anunciaban las restricciones perimetrales impuestas por el Gobierno y los protocolos a seguir para luchar contra la COVID-19 (Ver Figura 9).
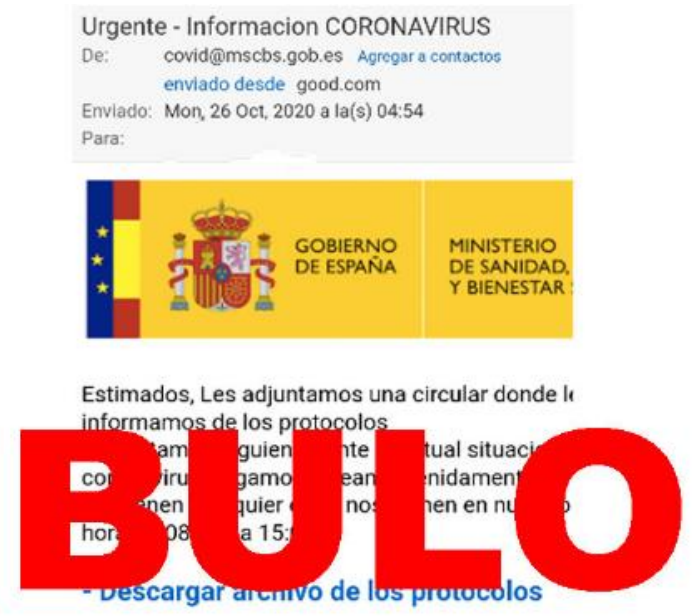

Figura 9: Mail distribuidor de malware Fuente: Maldita.es

El resto, hasta 17, responde a la técnica del pishing, un método usado por los ciberdelincuentes para conseguir datos de carácter personal como pueden ser contraseñas, tarjetas de crédito y números de cuentas bancarias, entre otros. Para la consecución de estos datos, las noticias, principalmente difundidas por WhatsApp, ofrecen un link para la obtención de "bonos para toda la familia" (Ver Figura 10), descuentos de hasta el 25\% para clientes de lberdrola, el reembolso de 345 euros por 
parte de la Seguridad Social e, incluso, la donación de zapatillas por parte de Nike y Adidas, entre otros.

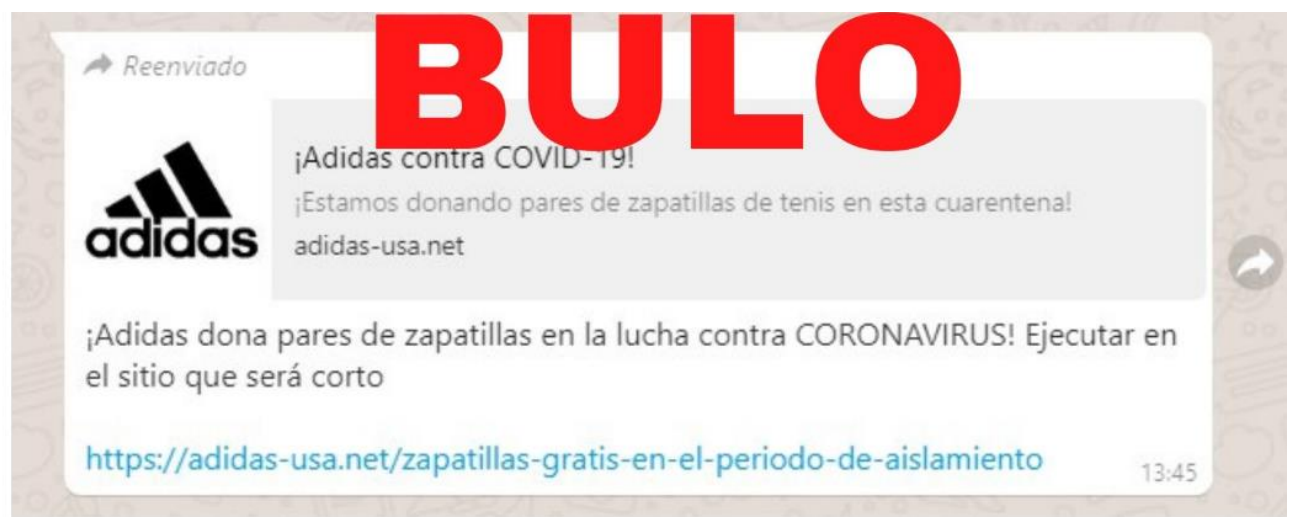

Figura 10: WhatsApp que anuncia la donación de zapatillas por Adidas

Fuente: Maldita.es

\section{CONCLUSIONES}

La incertidumbre y el miedo por la pandemia de coronavirus que asola al mundo desde hace más de un año han provocado un aluvión de informaciones falsas que ofrecen datos y opiniones variadas en torno a la enfermedad y sus repercusiones. Las aplicaciones de mensajería instantánea junto con las redes sociales se han convertido en la principal vía de difusión de estas noticias que, amparándose en la veracidad que se suele dar a todo lo recibido por los nodos de confianza, han generado una viralidad del fenómeno sin precedentes.

En el ámbito empírico, el presente estudio confirma lo ya apuntado por Salaverría et al. (2020) quienes destacan que las aplicaciones de mensajería instantánea, y en especial WhatsApp, son las plataformas elegidas para diseminar en mayor cantidad y alcance las informaciones falsas. Al estar pensadas para preservar la privacidad de las comunicaciones, imposibilita el monitoreo de los contenidos, "de ahí que se le conozca como un entorno social oscuro o dark social" (Cortés e Isaza, 2017, p.11). La mayoría de estos mensajes refrendan teorías conspiranoicas o persiguen captar la atención con titulares alarmistas que despiertan el lado emocional de unos receptores que, en tiempos de excepcionalidad, poseen el umbral del miedo más bajo y son más susceptibles de compartir mensajes que resultan amenazantes.

Le siguen en importancia las redes sociales, su papel en la difusión de información poco fiable (cercano al $40 \%$ ) está motivada por la necesidad que experimentan los ciudadanos de sentirse parte del flujo informativo, de formar parte de lo que se denomina el "ruido mediático" y ser portadores de titulares. Para combatir esta difusión indiscriminada de información, las principales redes sociales han puesto en marcha proyectos como Facebook Journalism, que monitorea el efecto de las noticias falsas para combatirlas mediante filtros, o Birdwatch, de Twitter, que permite identificar información engañosa en los tuits y escribir notas que brinden un contexto informativo.

Estos proyectos, junto a iniciativas de alfabetización mediática, se perfilan como el método más eficaz para batallar las mentiras y la desinformación en un entorno 
marcado por el consumo multicanal. Estas campañas pedagógicas están orientadas, principalmente, hacia los más jóvenes, no para decirles dónde consumir la información, sino para que valoren qué es la buena información. Se trata de educar partiendo de una actitud de ayuda y respeto, y con objeto de fomentar un razonamiento crítico basado en hechos reales contrastados, para, de esta forma, romper con la polarización ideológica.

Al igual que en investigaciones precedentes (Gutiérrez-Coba et al.,2020; Brenen et al.,2020), el formato de la mayoría de los bulos transmitidos fue de tipo texto (85\%), dada la "facilidad para manipularlo y distribuirlo por redes sociales, aplicaciones de mensajería o correos electrónicos" (Gutiérrez-Coba et al.,2020, p.258). Se observa, asimismo, como con objeto de hacer más creíble las informaciones y de apelar a los sentimientos de los receptores, un $15 \%$ poseía formato audio o audiovisual. Por el contrario, no se ha detectado el uso de deepfakes, una técnica de inteligencia artificial que valiéndose de la manipulación permite editar vídeos falsos de personas que aparentemente son reales para viralizar el mensaje.

El estudio del origen de los bulos en torno al coronavirus ha puesto de manifiesto que, si bien las guerras se libran ahora en un escenario muy distinto como es Internet, su origen sigue siendo, como apuntaba Tucídides en su Historia de la guerra del Peloponeso, el miedo y el interés. Precisamente, el miedo, entendido como el sentimiento de desconfianza que impulsa a creer que va a ocurrir algo negativo, es la base de los bulos de origen conspiranoico (36\%) que se articulan en virtud de que hay una verdad que nadie quiere que se conozca. Cuanto más interés despierte este tipo de información más fácilmente será creída y difundida y para ello es imprescindible la inclusión de datos que hagan verdadero daño en algo tan concreto y efímero como puede ser la salud.

De igual forma, el interés (ideológico, económico y político) constituye la segunda gran razón presente en el origen de los bulos. Interés económico (27\%), bien por estafa o por el rédito obtenido por la viralidad de noticias en las que conseguir lectores a toda costa juega en detrimento de la calidad periodística de los textos; interés ideológico (18\%), bien sea de tipo geoestratégico o social (xenofobia, aporofobia...), aún a costa de poner en juego la estabilidad de las relaciones diplomáticas entre países; e interés político (19\%), para denostar el punto de vista del contrario y, de paso, desacreditarle ante la opinión pública, sin tener en cuenta que el bienestar de los ciudadanos y su derecho a una información veraz debe prevalecer, máxime en situaciones excepcionales de pandemia.

Ante este panorama de infodemia, la pedagogía de la verificación de datos es más importante que nunca y, en este sentido, resulta fundamental el trabajo desempeñado por las principales redes sociales por eliminar de sus tableros cualquier tipo de información no contrastada, así como la labor de los Cuerpos de Seguridad del Estado, principalmente, Policía Nacional y Guardia Civil, encargados de desmentir bulos a través de sus plataformas digitales. Sin embargo, es el Periodismo el auténtico guardián de la veracidad informativa, bien a través del ejercicio responsable e ideológicamente neutral de los medios de comunicación o, a posteriori, gracias a la labor periodística desarrollada por las plataformas de fact-checking, encargadas de desmentir rápidamente las informaciones falsas, siempre con un escrupuloso respeto al derecho 
a la libertad de expresión y a la crítica y con objeto de evitar el estrés social que generan estos bulos.

Son precisamente las plataformas de verificación datos la principal limitación metodológica de este estudio, ya que realizan su trabajo de clasificación y estudio con base en criterios subjetivos de relevancia y peticiones de los propios usuarios. Para superar esta limitación, también presente en Salaverría et al. (2020), sería aconsejable lo propuesto por dichos autores, un estudio fundado en la detección y análisis de las noticias publicadas en las redes sociales y plataformas de difusión masivas, mediante metodologías de big data.

\section{REFERENCIAS}

Alcalde, S. (2020, 29 de abril). Bulos de animales durante el confinamiento por el coronavirus. National Geographic. https://bit.ly/3x8wqwn

Alonso-González, M. (2019). Fake News: desinformación en la era de la sociedad de la información. Ámbitos. Revista Internacional de comunicación, 45, 29-52. http://doi.org/10.12795/Ambitos.2019.i45.03

Blanco, P. (2020, 23 de marzo). ¿A quién beneficia la avalancha de bulos sobre el coronavirus? El País. https://bit.ly/34W774v

Brennen, J. S., Simon, F. M., Howard, P. N., \& Nielsen, R. K. (2020). Types, Sources, and Claims of COVID-19 Misinformation. Reuters Institute for the Study of Journalism. https://bit.ly/3v07A00

Casero-Ripollés, A. (2020). Impact of Covid-19 on the media system. Communicative and democratic consequences of news consumption during the outbreak. Profesional de la información, 29 (2). http://doi.org./10.3145/epi.2020.mar.23

Consejo de la Unión Europea (2018). Plan de Acción contra la Desinformación. https://bit.ly/2T4e2py

Cortés, C. e Isaza, L. (2017). Noticias falsas en Internet: La estrategia para combatir la desinformación. Universidad de Palermo. https://www.palermo.edu/cele/pdf/FakeNews.pdf

Diario de Fuerteventura (23 de junio de 2020). El Cabildo trasladará a Fiscalía "bulos" difundidos por una web vinculada al consejero Domingo Pérez (PP). Diario de Fuerteventura. https://cutt.ly/enkYBUI

EFE (2020, 5 de agosto). Creadores de bulos, ¿Qué hacen y cómo lo hacen? https://bit.ly/3g3giZX

Facebook (2020, 24 de junio). Invertir en iniciativas de alfabetización mediática en los EE.UU. https://www.facebook.com/journalismproject/media-literacy-initiatives 
Gallego, C. (2020). Fake News en tiempos de COVID. La invasión de la desinformación. BAE Business School. http://marketing.eae.es/prensa/SRC FakeNews.pdf

Gonzalo, M. (2020, 10 de agosto). Ciberataques en tiempos de pandemia. Newtral. https://www.newtral.es/ciberataques-pandemia/20201008/

Grau, A. (2008, 10 de octubre). Internet cambia la forma de leer... ¿y de pensar? El País. https://bit.ly/3ghPW2p

Gutiérrez-Coba, L. M., Coba-Gutiérrez, P. y Gómez-Díaz, J. A. (2020). Noticias falsas y desinformación sobre el Covid-19: análisis comparativo de seis países iberoamericanos. Revista Latina de Comunicación Social, 78, 237-264. https://doi.org/10.4185/RLCS-2020-1476

Instituto Nacional de Estadística (2020, 16 de noviembre). Encuesta sobre Equipamiento y Uso de Tecnologías de Información y Comunicación en los Hogares. https:// www.ine.es/prensa/tich 2020.pdf

Kapferer, J. N. (1988). Boatos. O meio de comunicação maisvelho do mundo. Publicaciones Europa-América.

Keane, J. (2013). Democracy and media decadence. Cambridge University Press.

López-Borrull, A., Vives-Gràcia, J., \& Badell, J. (2018). Fake news, ¿amenaza u oportunidad para los profesionales de la información y la documentación? El profesional de la información, 27(6), 1346-1356. https://doi.org/10.3145/epi.2018.nov.17

López-Borrull, A. (2020a). Bulos científicos, de la tierra plana al coronavirus, el impacto negativo que las mentiras. Oberon

López-Borrull, A. (2020b). Fake News y coronavirus: la información como derecho y necesidad. Revista de los Estudios de Ciencias de la Información y de la Comunicación, 98.

López-Rico, C., González-Esteban, J. L. y Hernández-Martínez, A. (2020). Polarización y confianza en los medios españoles durante el Covid-19. Identificación de perfiles de audiencia. Revista Española de Comunicación en Salud Suplemento 1, 77-89. https://doi.org/10.20318/recs.2020.5439

Lázaro-Rodríguez, P. y Herrera-Viedma, E. (2020). Noticias sobre Covid-19 y 2019CoV en medios de comunicación de España: el papel de los medios digitales en tiempos de confinamiento. Profesional de la información, 29 (3). https://doi.org/10.3145/epi.2020.may.02

Mantzarlis, A. (2018). Fact-checking 10 in C. Ireton \& J. Posetti (eds.), Journalism, Fake News \& disinformation: Handbook for journalism education and training (pp. 85-100). Unesco. 
Nielsen, R., Fletcher, R., Brennen, J., \& Howard, P. (2020). Navegando la "infodemia": así consume y califica las noticias y la información sobre el coronavirus la gente en seis países. University of Oxford.

Ocaña, J. (28 de julio de 2020). Conspiraciones en tiempos de virus. El Heraldo. https://bit.ly/2Rvb3WK

Orden PCM/1030/2020, de 30 de octubre, por la que se publica el Procedimiento de actuación contra la desinformación aprobado por el Consejo de Seguridad Nacional, 292, de 5 de noviembre de 2020, 96673-96680. https://www.boe.es/eli/es/o/2020/10/30/pcm1030

Pozo-Montes, Y. y León-Manovela, M. (2020). Plataformas fact-checking: las Fake News desmentidas por Newtral en la crisis del coronavirus en España. Revista Española de Comunicación en Salud, 1,103-116. https://doi.org/10.20318/recs.2020.5446

Ricou, J. (2020, 14 de febrero). El contagio imparable del miedo: cuando la emoción gana a la razón. La Vanguardia. https://bit.ly/3g2tB9c

Rouco, F. (2020). Las estrategias de propaganda mutan durante la pandemia. Telos, $114,18-21$.

Salaverría, R., Buslón, N., López-Pan, F., León, B., López-Goñi, I., y Erviti, M. C. (2020). Desinformación en tiempos de pandemia: Tipología de los bulos sobre la Covid-19. El Profesional de la Información, 29(3), 1-15. https://doi.org/10.3145/epi.2020.may.15

Sánchez-Castrillo, A. (2020, 27 de mayo). De los Ultracatólicos de Hazte Oír a Resistencia Democrática: ¿Quién es quién tras las protestas contra el gobierno? InfoLibre. https://bit.ly/3fH]jMI

Stencel, M. \& Luther, J. (2020, 13 de octubre). Fact-checking count tops 300 for the first time. Duke Reporter's Lab. https://bit.ly/2TPPukA

Sunstain, C. (2009). On rumours. How falsehoods spread, Why we believe them, What can be done. Penguin.

Tucídides (2013). Historia de la Guerra del Peloponeso: Traducción, introducción y notas de Francisco Rodríguez Adrados. Amazon Kindle.

Useche (2008). Miedo, seguridad y resistencias: el miedo como articulación política de la negatividad. Polis, Revista Latinoamericana, 19, 1-27. https://journals.openedition.org/polis/3893

We are social (2021, 27 de enero). Digital 2021, Global Overview Report. https://wearesocial.com/digital-2021 
White, A. (2020, 27 de marzo). Historical linkages: epidemic threat, economic risk, and xenophobia. The Lancet. https://bit.ly/3wPiKGi

\section{AUTOR/ES:}

\section{Marián Alonso-González}

Marián Alonso González es Doctora en Comunicación por la Universidad de Sevilla (2008) con una Tesis Doctoral que versa sobre el cambio tecnológico de $A B C$ de Sevilla. Miembro de la Asamblea de Mujeres Periodistas de Sevilla y del Censo de Expertas, compagina su labor profesional como Técnico de Comunicación en Adif con su labor docente como profesora asociada en la Facultad de Comunicación de Sevilla, donde imparte clases de nuevas tecnologías y redacción. Especializada en redes sociales, ha orientado su investigación a campos relacionados con la Comunicación 2.0, el Periodismo 3.0, las audiencias sociales y los nuevos lenguajes multimedia e interactivos.

malonsog@us.es

Orcid ID: https://orcid.org/0000-0003-2676-0449

Google Scholar: https://scholar.google.com/citations?user=pTW9yp0AAAAJ\&hl=es

ResearchGate: https://www.researchgate.net/profile/Alonso Marian

Scopus: ID:57000544900

Academia.edu: https://us.academia.edu/Mari\%C3\%A1nAlonso 